\title{
As idéas de soberania, autonomia e federaçãa
}

$\mathrm{Na}$ apprehensão dos factos da ordem politica, tres idéas têm sido muito confusamente percebidas: a da soberania, a da autonomia, a da federação.

A idéa de soberania tem, como notas caracteristicas, a unidade e a totalidade; e por isso, como diz Schutzenberger, é uma applicação da formula do absoluto. Este pensamento não é mais do que a reproducção do principio desenvolvido na "Politica», de Aristoteles : - a soberania é uma e indivizivel, ut omnes partem habeant in principatu, non ut singuli, sed ut universi. Vamos verificar como esta concepção genial se manifesta, de um modo completo, na realidade das cousas.

$O$ direito se nos revela, quer como attributo da pessốa (direito subjectivo), quer como phenomeno na vida social (direito objectivo material), quer como nórma de agir ou lei (direito objectivo formal). A pessôa, o individuo, que é o sujeito do direito, emquanto não reclama a intervenção do poder social, é considerado ut singulus; mas, desde que reclama a intervenção do poder social, é considerado ut uni versus. O direito, mantido pelo poder social, representa uma idéa universal, unum in pluribus et sin- 
gillatim de pluribus. Exprime a vontade da nação inteira communicada ao individuo:-unum communicabile pluribus.

Neste sentido, considerada a realidade da vida social, o direito objectivo se torna subjectivo quando ha uma relação de identidade entre a vontade geral e a vontade individual; porque sómente então a primeira communica o seu poder á segunda. O direito, em sua realisação na vida social, é a vontade geral, a vontade de uma nação, tornada concreta e viva na pessôa privada. Eis como Ihering explica este phenomeno: " $\mathrm{O}$ direito do individuo deve ficar em relação com a vontade geral, de tal modo que a vontade individual não possa exercer-se senão coberta pela vontade geral; a vontade geral communica sua potencia á vontade individual, de sorte que o direito objectivo torna-se subjectivo, a nórma de agir confunde-se com a faculdade de agir.»

A vontade geral de uma nação é o que se chama soberania nacional. A soberania nacional, uma e indivisivel, communica-se ao individuo, quando este reclama o seu direito violado ou ameaçado. $\mathrm{O}$ individuo exerce o seu direito ut singulus; mas, quando reclama a intervenção do poder publico, invoca, ut universus, a soberania nacional. A soberania nacional, permanecendo uma e indivisivel, communica-se aos individuos, como o sol que, comquanto unico, illumina todas as criaturas.

Ha, na natureza, um fluido que é a força unica, cujas vibrações produzem o calôr, a luz, a electricidạde, o magnetismo e até a gravidade: fluido imponderavel, impalpavel, incoercivel, que causa todas as acções thermicas e chimicas dos corpos por um movimento de rotação e translação, que lhe é proprio e cuja energia é sempre conservada. Tudo na natureza depende do movimento deste fluido unico por suas ondulações nos corpos. A soberania nacional é analoga a esse fluido, que, por suas vibrações nos poderes publicos ou nos seus orgams, garante a realisação do direito nas relações dos individuos.

Não ha duas soberanias, nem meia soberania. A soberania é uma força simples, infraccionavel: ou 
existe toda, ou não existe. E' um principio de actividade, fórma simples, localisada na materia extensiva, de tal sorte que existe toda inteira em cada parte material e toda inteira no conjuncto da materia. E' um principio vital, que está ao mesmo tempo em todo o corpo vivo e em cada uma de suas partes, ainda que não exerça a variedade de suas faculdades senão na variedade dos orgams correspondentes a cada uma dellas. E' a alma de uma nação; é a unidade do direito, quer na sua definição, quer na sua applicação ás relações dos individuos que compõem a nação. A isto é que os philosophos chamam universale reflexum. $\mathrm{O}$ direito deve ser applicado tal como é definido: é a Nação, por seu poder legislativo quem o define : é a Nação, por seu poder judiciario, quem o ajplica. O individuo, quando provoca o poder judiciario, quer na jurisdicção federal, quer nas jurisdições estaduaes, invoca a Nação.

Temos necessidade de firmar estas idéas, porque nós vivemos em um Estado Federal disposto em Estados federados. Alguns pretendem vêr no Estado Federal uma soberania dual, e, em cada Estado federado, uma fracção de soberania: ísto não é sómente um erro; é mais do que um erro, é uma falsidade; é mais do que uma illusão, é uma chimera. A soberania não está nem no Estado Federal nem nos Estados federados; tanto aquelle, como estes, não passam de organismos para as funcções da soberania, que decorrendo, só, toda e uma, da Nação inteira, persiste só, toda e uma, na Nação inteira.

Schützenberger, nas Leis da Ordem Social, II, cap. I e II, exprime brilhantemente este conceito, nos seguintes trechos:

"A idéa da soberania exprime a natureza da potencia psychica do eu individual ou social; applicada ao poder social, a idéa da soberania designa o poder social em sua unidade, em sua totalidade, em sua potencia uma e indivisivel; ella implica a formula do absoluto applicada ás forças intellectuaes e moraes, a qual, na realidade da ordem politica, corręsponde a potencia psychica do eu social. A formula que attribue a soberania á nação, é a unica racional; é a formula 
da idéa social do direito e do dever, reflectindo a consciencia geral de uma nação, produzindo a lei suprema das vontades individuaes e da vontade social na ordem juridica.

«A soberania differe dos poderes, como a causa differe dos effeitos, como a potencia de agir differe dos modos de acção. A potencia psychica do homem age por intermedio de suas faculdades, que têm orgams com funcções correspondentes; a potencia psychica da nação age por intermedio dos poderes publicos, que tambem tem orgams e funcções. Cada orgam do poder social exerce, nos limites de suas funcções, a actividade da soberania».

Nem outra cousa resulta da Constituição da Republica, promulgada em 24 de Fevereiro de 1891. Alli dominou, em todo o contexto, não o paradoxo de Proudhon, mas a recta observação de Hamilton: a autonomia dos Estados federados, por mais ampla que seja, não poderá passar daquillo que se refere aos seus interesses "proprios", unicos que podem depender de sua acção directa e immediata. Os interesses «communs» da Nação, (dentre os quaes o mais importante, que é a realisação dos direitos individuaes, depende de acção indirecta e mediata do poder social), - esses nunca poderão estar subordinados a essa autonomia; a lei, que o define, é uma lei "nacional»; e, para applicar essa Jei "nacional», é que existem juizes, quer na jurisdicção federal, quer nas jurisdicções estaduaes. O poder judiciario é sempre uma delegação da soberania nacional, quer na jurisdicção federal, quer nas jurisdicções estaduaes; o juiz brasileiro, qualquer que elle seja e qualquer que seja a materia de sua competencia, profere a sua sentença, não em nome do Estado, mas em nome da Nação. A soberania dos Estados é, portanto, uma chimera, tão monstruosa como a chimera da fabula; cabeça de leão, corpo de cabra e cauda de dragão. A soberania é da Nação Brasileira, só, toda e uma; a idéa da soberania é inconcebivel sem as notas da «unidade e da totalidade». 


\section{I}

Isto não quer dizer que os Estados federados deixem de ter "autonomia", no verdadeiro sentido desta palavra. Que significa «autonomia"? Significa "direcção propria daquillo que é proprio». Ora, o direito individual não é proprio do Estado, é proprio do individuo; e a lei que o define e regula, é "commum" da Nação inteira. O proprio do Estado federado é a organisação dos funccionarios incumbidos de julgar : a definição das funcções, em relação á lei e á acção da lei, essa é "commum» á Nação inteira, da qual todos os juizes são delegados, qualquer que seja a sua jurisdicção, qualquer que seja a sua competencia material, e qualquer que seja o seu districto territorial.

$\mathrm{Na}$ orbita das relações de direitos individuaes, a acção dos Estados federados é toda mediata e indirecta; a sua acção está, pois, naturalmente subordinada á soberania nacional. Não acontece outro tanto nas relações puramente sociaes, em que a acção dos Estados é directa e immediata; nesta orbita é que se revela a sua autonomia, porque então o seu interesse é proprio e não commum á Nação inteira: assim é, não só na organisação de seús funccionarios, em que a sua autonomia é de caracter politico, e no seu desenvolvimento interno e economico, em que a sua autonomia é de caracter administrativo.

A autonomia, em summa, é a propria direcção daquillo que é proprio; sómente por extensão, puramente metaphorica, é que se costuma tambem attribuir a autonomia a quem, por acção propria, dirige aquillo que não the é proprio. Mas, o "proprio" póde ser absoluto ou relativo; ou, como diz o Philosopho (nos "Topicos», V. cap. I), proprium est per se seu absolutè, relate seu ad aliquid, et aliquando. Por outro lado, o proprium, quando não é absoluto, póde convir omni sed non soli, ou soli sed non omni. Dahi a possibilidade de uma cumulação, que, quando não seja simultanea nem alternativa, ha de ser sempre suppletiva, prevalecendo a soberania nacional, nos casos em que estejam em jogo direitos individuaes, prevalecendo a autonomia local nos casos em que esteja em jogo apenas e puramente o interesse da acção 
social, directa e immediata, dos governos locaes. A Constituição da Republica, na sua redacção, exprimiu perfeitamente os effeitos destas distincções, que tanto têm de escolasticas quanto de reaes.

Assim, a autonomia politica dos nossos Estados federados, na organisação de seus funccionarios, ha de subordinar-se aos principios constitucionaes da União, na forma do artigo 63 da Constituição da Republica, «ibi»: "Cada Estado reger-se-á pela Constituição e leis que adoptar, respeitados os principios constitucionaes da União».

Quanto á autonomia administrativa, posto que o Estado federal não esteja inhibido de estender a sua acção aos Estados federados, esta intervenção jamais poderá tolher a acção dos governos locaes; o Congresso Nacional, na forma do artigo 35 da Constituição da Republica, póde animar, em todo o paiz, o desenvolvimento da instrucção, bem como a immigração, a agricultura, a industria e o commercio, mas «sem privilegios que tolham a acção dos governos locaes".

Quanto ao processo nas jurisdicções estaduaes, os Estados federados não podem legislar sobre a forma, quer intrinseca, quer extrinseca, dos actos processuaes, porque a forma affecta a acção das leis que regulam os direitos individuaes, que são um interesse "commum" da Nação inteira. As decisões dos seus juizes e tribunaes; "uma vez passadas em julgado», porão termo aos processos, salvo quanto a habeascorpus e espolio de estrangeiros, que, por sua natureza, não estabelecem uma situação constante e immutavel; mas, nada impede que as sentenças proferidas na suprema instancia dos juizes ou tribunaes dos Estados, emquanto não passam em julgado, fiquem sujeitas a recurso perante o Supremo Tribunal Federal, que, conhecendo da "mesma causa", constitue "fatalmente» outra instancia: instantia est existentia fluens, id est, identitas mobilis aut quadam unitas ducta in numerum prioris est posterioris. O movel, no processa, é a causa: essa causa, isto é, a relação entre o direito e o facto, posta em controversia, tal como ficou fixąa na contestação da 
lide, permanece em litigio perante o Supremo Tribunal Federal. Estas consequencias resultam dos arts. 34, n. 23, e 59 paragrapho primeiro, da Constituição da Republica. A autonomia dog Estados não tem applicação a estes casos, porque, referindo-se elles á relações de direitos individuaes, não envolvem interesse "proprio" do Estado, mas "proprio" do individuo e regulado por uma lei "commum» da Nação.

\section{I I}

Estas distincções resolvem as theorias sobre 0 "selfgovernment" e a "selfadministration", dos inglezes, sobre a "Selbstregierung» e a "Selbstverwaltung», dos allemães, expostas em Bluntschli, na «Politica", cap. V; e, do mesmo modo, resolvem não só as theorias sobre a centralisação e descentralisação, expostas em Schützenberger, nas «I,eis da Ordem Social», como as theorias sobre a federação.

A federação não é uma "composição", mas sim uma "disposição" de partes, chamem-se estas provincias, quando apenas têm a autonomia adıninistrativa, chamem-se Estados, quando se lhes confira uma autonomia politica na organisação de seus funccionarios. A «composição» suppõe partes separadas ou separaveis do todo; a "disposição " suppõe partes inherentes ao todo, ou como diz o Philosopho, ordo partes habentis, aut secundum locum, aut secundum potentiam, aut secundum speciem. Nisto se distingue a federação da confederação: na federação não ha partes a compôr, ha partes a dispôr; na confederação ha partes a compôr e a dispôr.

Mas, mesmo nesta "disposição», não ha accordo entre os publicistas: uns, como Proudhon, affirmam que "o que faz a essencia e o caracter do contracto federal, é que os Estados reservam para si, formando um pacto, mais direitos, mais liberdades, mais poderes, do que os que deixam á União»; outros, como Alexandre Hamilton, affirmam que "na federação, cada Estado particular fica no dominio dos seus interesses "proprios", ao passo que a União fica no dominio dos interesses "communs". 
A theoria de Proudhon foi, desde logo, repellida como tendente a confundir a federação com a confederação, e a formar mais uma associação de Estados do que uma união federal. Prevaleceu a theoria de Hamilton.

Dir-se-á que a autonomia, mesmo restricta aos interesses "proprios", importa uma soberania dos Estados particulares, desde que a estes fica o direito de constituir o seu organismo e de exercer livremente as respectivas funcções. Mas, em primeiro logar, essa autonomia, ampla na constituição do organismo, é restricta naquillo que as funcções deste organismo possam referir-se a interesses "communs" da nação; e assim, deixando de ser absoluta, isto é, uma e total, deixa ipso facto de ser soberana. Em segundo logar, essa autonomia é attribuida aos Estados particulares, não por virtude dos mesmos Estados, porém, por virtude da soberania nacional, manifestada na Constituição Federal; por conseguinte, não é uma força inherente aos mesmos Estados, mas uma força que lhes é conferida pela Nação.

Os Estados particulares têm um poder legislativo e um poder executivo, para regerem-se em seus interesses "proprios", que dependem de sua acção directa e immediata; quanto ao poder judiciario, esse é eminentemente nacional, tanto na jurisdicção federal, como nas jurisdicções estaduaes, porque a sua acção, dependendo de provocaçã̃o do individuo, é sempre indirecta e mediata, e applica-se a direitos regulados por uma lei "commum" da Nação. Os juizes e tribunaes, mesmo nas jurisdicções estaduaes, só se applicam a conhecer e julgar de relações de direito ; não attingem, portanto, interesse . "proprio» do Estado, mas "proprio" do individuo e subordinado a leis "communs» da Nação inteira. Não ha poder judiciario federal, assim como não ha poder judiciario estadual; todo o poder judiciario, quer na jurisdicção federal, quer nas jurisdicções estaduaes, é só e eminentemente "nacional». As locuções - "poder judiciario federal" e "poder judiciario estadual", não passam de uma metalepse, exprimindo as respectivas jurisdicções. 
Bluntschli, depois de apontar os defeitos da "confederação", que levaram os Estados-Unidos da America do Norte, a Suissa e Allemanha, a se transformar em "federações", mostra como a logica das cousas, pela força do sentimento nacional, tolerando e quiçá applaudindo a autonomia dos Estados no que diz respeito aos seus interesses "proprios» - não supporta esta autonomia no que diz respeito aos direitos individuaes. Estes direitos, que são o interesse "commum" da Nação inteira, só podem ser regulados, quer na sua definição, quer na sua applicação, por poderes delegados da soberania nacional, quer no organismo da União, quer nos organismos dos Estados particulares federados.

Schäffle, na sua "Estructura e vida do corpo social", tentando mostrar a semelhança da anatomia, physiologia e psycologia do corpo social, com a anatomia, physiologia e psycologia do corpo humano, mostra, por uma analogia com o systema nervoso, que a autonomia do systema ganglionario, (cujos gangliões representam os Estados particulares federados, dos quaes os municipios são cellulas), - sómente é concebivel naquillo que diz respeito á sua acção immediata na vida de nutrição, e nunca naquillo que possa, mesmo por sua acção indirecta e mediata, affectar a vida de relação, nem naquillo que sómente consista na vida de relação, toda dependente do systema cerebro-espinhal, que é o Estado Federal. Aliás, diz elle, a physiologia tem provado que o funccionamento do systema ganglionario está subordinado á sua connexã̃o com o systema cerebro-espinhal, de sorte que não podemos figural-o como anatomicamente independente; elle conduz aos centros nervosos superiores ou ao encephalo excitações que não provocam acções reflexas immediatas. Apreciados os orgams motores e sensitivos do corpo organico, por mais variados que sejam, observaremos no seu funccionamento a unidade do principio vital, que no homem é a alma, na sociedade é a soberania, e que, portanto, no corpo social de uma nação, não póde deixar de ser a soberania nacional.

Sempre firmado nesta analogia, Schäffle concebe a possibilidade de uma autonomia das cellulas sociaes, 
desde que esta actividade autonoma não perturbe a vida de todo o corpo social. Relativamente ás familias e municipios, a autonomia administrativa, em geral, não perturba esse resultado; mas, em relação á autonomia politica, que consiste na liberdade de legislar e organisar-se, e que dá a essas partes o predicamento de "Estados", essa não póde deixar de ser ligada á coordenação necessaria á conservação do todo, isto é, está restricta pela subordinação dos direitos individuaes ás regras que sejam ou possam ser definidas pela lei commum, e á preeminencia do interesse commum, em tudo quanto se possa adaptar ao interesse collectivo; em rigorosa consequencia, a autonomia politica dessas partes estaduaes consiste na organisação dos funccionarios, sempre porém, em sua substancia, subordinadas a typos adaptaveis ao movimento complexo e inseparavel da unidade do principio vital que anima todo o corpo social.

Os poderes federaes do Estado Federal, assim como os poderes estaduaes dos Estados particulares federados, nada mais são do que o organismo nacional, um em sua substancia e vario nas modificações relativas á actividade dos orgams: o Estado Federal é sempre o orgam da integração da politica, da legislação e da administração; os Estados particulares federados apenas são capazes de vida completamente autonoma naquillo que não affecta a administração integral, isto é, na administração daquillo que lhes é "proprio»; e a sua autonomia politica na organisação de seus funccionarios, em tudo quanto do exercicio das funcções, possa affectar o interesse commum da nação, é limitada pela coordenação, pela supraordenação e, em alguns casos, pela subordinação. Em summa, as organisações estaduaes, analogas á do systema ganglionario ou grande sympathico do systema nervoso, si podem ter uma acção á parte independente do Estado Federal, cuja organisação é analoga á do encephalo ou systema cerebro-espinhal, nem por isso deixam de estar em relação por uma multidão de interesses communs, que equivalem ás anastomoses ou articulações nervinas. A conclusão da theoria de Schäffle resulta de uma analogia, cuja extensão póde ser apreciada pelos leitores; mas, seja 
qual fôr o ponto de vịsta em que nos colloquemos, jámais conseguiremos dar aos Estados particulares federados a qualidade de soberanos, nem desligal-os da connexão com o Estado Federal, naquillo que póde affectar os direitos individuaes e outras relações ligadas ao interesse commum da nação.

Os mais notaveis publicistas norte-americanos, apurados pela experiencia, assignalam a real situação das cousas. Dentre elles, o conhecido Cooley, depois de mostrar que o povo americano teve necessidade de repellir os "Articles of Confederation» de 1777, para substituil-os pela *Constitutional Law», de 1787, diz o seguinte: "Os Estados tinham sido chamados "were called» soberanos e até independentes; mas, nunca, em seu caracter individual, deixaram de ser subordinados, em relação aos mais altos poderes da soberania, a uma autoridade commum, e nunca foram reconhecidos separadamente como soberanos; aliás, 0 termo - soberania "in its full sense imports the * supreme, absolute, and incontrolable power".

\section{V}

A Constituição da Republica Brasileira, aproveitando todas essas lições da doutrina e da experiencia, teve o maxímo cuidado na sua redacção, não deixando duvida sobre os seguintes pontos:

$1 .^{0}$ - A Nação Brasileira não foi instituida pelos Estados federados: existiu antes delles e existe nelles e com elles. A Nação Brasileira, diz o art. $10^{\circ}$ da Constituição, "constitue-se» por união perpetua e «indissoluvel» de suas antigas provincias em EstadosUnidos do Brasil. O adjectivo "indissoluvel » não está por demasia; não basta que a união seja perpetua, é preciso firmar que ella é "indissoluvel», porque a unidade do Brasil não é uma unídade de "composição", nem uma unidade de "aggregação": é unidade "formal", isto é, indivisivel na substancia, posto que divisivel nos accidentes.

$2^{\circ}$ - Aos Estados é "conferida a autonomia politica apenas para se organisarem; e a autonomia administrativa em tudo quanto, affectando sómente os 
seus interesses "proprios", depender de sua acção directa e immediata. Cada Estado reger-se-á pela Constituição e leis que adoptar, "respeitados os principios constitucionaes da União» (art. 63); e lhes é "facultado", em geral, todo e qualquer poder ou direito. que lhes não fôr negado por clausula expressa ou «implicitamente contida» nas clausulas expressas da Constituição da Republica (artigo 65). Isto significa que a autonomia dos Estados não se exerce em relação ás regras sobre direitos individuaes, quer em sua definição, quer em relação ás fórmas da sua applicação, nem em relação a qualquer outro caso que possa affectar o interesse "commum» da Nação.

$3 .^{\circ}$ - A Constituição da Republica deixou ainda bem sensivel, no artigo $4 .^{\circ}$, que os Estados não constituem uma unidade "formal", visto que, com approvação do Congresso Nacional, podem incorporar-se entre si, subdividir-se, ou desmembrar-se; e dahi decorre, como importante restricção até para a personalidade juridica dos Estados, que estes, não podendo, perante as nações estrangeiras e perante o direito civil internacional, ser considerados, segundo a locução de Ulpiano ( $X X$, paragrapho 5), um certım corpus, - não podem, sem a intercessão do Congresso Nacional, contrair emprestimos externos. Esta possibilidade de divisão e desmembramento, caracterizando uma contingencia em cada Estado, reflecte sobre a sua capacidade na personalidade juridica, em relação aos compromissos externos: do art. $4^{\circ}$ da Constituição da Republica resulta que a integridade não é uma nota "essencial» dos nossos Estados federados; cada Estado, não constituindo uma unidade «indissoluvel», torna-se, perante o Direito Civil Internacional, um incertum corpus, que, por si só, não póde garantir obrigações para o futuro.

$4 .^{\circ}$ - Os municipios não têm qualquer autonomia politica; por isso, não podem organisar-se. A sua organisação é conferida aos Estados; elles têm, entretanto, autonomia administrativa naquillo que, sendo de seu interesse "absolutamente proprio" ou peculiar, depender de sua acção directa e immediata (art. 68). Mas, o municipio, mesmo perante o Direito Publico interno, - é um incertum corpus, visto que, 
em qualquer tempo, póde ser dividido, desmembrado, ou limitado por lei do Estado.

$5 .^{\circ}$ - Dahi decorre, em relação á personalidade juridica dos municipios, as seguintes restricções :$1 .^{\circ}$, não podem contrair emprestimos, mesmo internos, nem onerar rendas futuras, sem intercessão ou, ao menos, consentimento do Estado; $2 .^{\circ}$, não podem contrair emprestimos externos sem approvação do Estado e sem a intercessão do Congresso Nacional.

Já desde o Direito Romano se assignalava a influencia da falta de autonomia politica dos municipios sobre a extensão da sua capacidade na personalidade juridica. Cujacio, commentando a const. 6 do Cod., L. VI, tit. XXIV, que só permitte aos municipios adquirir, a titulo de herança, legado ou doação, casas, annonas civis, edificios e escravos, diz: quia incerta sunt corpora; e os tratadistas assignalam o verdadeiro sentido do texto de Ulpiano, notando que, comquanto não se trate de uma incerta persona, trata-se de um incertum corpus, cuja integridade, não dependendo de si, não póde garantir obrigações para o futuro. Os emprestimos contraidos pelos municipios dependem, portanto, ou da autorisação ou da approvação da legislatura estadual.

- Ha outras consequencias, posto que menos importantes, da força logica destes preceitos constitucionaes; em todo o caso, na Constituição da Republica, ficou perfeitamente firmado que a soberania nacional, só toda e uma, inteira e infraccionavel, é a base da federação. Qualquer projecto tendente a desconhecer essa soberania, impondo-lhe qualquer restricção, não póde, mesmo nos termos, do artigo 90, paragrapho 4. ${ }^{\text {, }}$, da Constituição da Republica, ser admittido como objecto de deliberação; qualquer projecto, que ponha em duvida a integridade e infraccionabilidade da soberania nacional, é acto de revolução

JoÁ MENDES JUNIOR 


\section{APPENDICE}

Já vimos que Schützenberger, Bluntschli e outros publicistas, comparando a Confederação com a Federação, mostram que a Federação, pelo natural appetite da unidade, foi substituindo a Confederacão, na Suissa, na Allemanha e na America do Norte : appetitus unitatis ita intimus et essencialis et universalis est in omnibus, diz Duns Scot. As tendencias imperialistas dos Estados Unidos da America do Norte estão, dia por dia, nos revelando essa irresistivel exigencia da natureza. Nós fomos um cimperios desde a chegada de D. João VI ao Rio de Janeiro em 1808; continuamos um aimperios com a denominação de Reino Unido em 1815; proclamamos solemnemente a nossa qualidade de aimperio» em 1822 e em 1824 com a Constituição da Monarchia ; mantivemos e mantemos a nossa qualidade de simperios, em plena republica, com a Constituição de 24 de Fevereiro de 1890.

Convem attender bem para as notas da idéa contida no termo cimperios, porque não é raro confundirem esta idéa com a idéa de despotismo, ou subordinæem-n'a á idéa de titulo honorifico de monarcha vitalicio. A idéa de cimperios tem duas notas: a da soberania nacional e a da grande extensão territorial. O termo «imperio" exprime, pois, a soberania nacional em uma grande extensão territorial, por mais liberaes que sejam as formas organicas da politica; em summa, exprime a unidade formal de uma grande nação. Nesse sentido, os Estados Unidos da America do Norte, em plena republica, tendem a aperfeiçoar o simperios; e o nosso Brasil, pela Constituição da Republica, manteve a sua qualidade de simperios.

A nossa nacionalidade principiou a formar-se pelo Manifesto de 1 de Maio de 1808, dirigido ás potencias, por D. João VI. Este Principe, então chegado ao Brasil, declarou, nesse Manifesto, que -a Corte de Portugal levanta a sua voz do novo Imperio que vae crear ; o segundo passo, esse realmente decisivo, foram os Alvarás de 22 de Abril e 10 de Maio desse mesmo anno de 1808, aquelle creando a Mesa do Desembargo do Paço e da Consciencia e Ordens do Rio de Janeiro, este transformando a Relação do Rio de Janeiro em Casa de Supplicação do Brasil, para terminarem ahi todos os pleitos entre individuos na final instancia.

Desde então, isto é, desde o Alvará de 10 de Maio de 1808, ficou o cindividuo», dependendo sómente do Brasil para a solução das suas relações de direito; isto é, os Alvarás de 22 de Abril e 10 de Maio de 1808 formaram a nacionalidade brazileira emancipando-a de Portugal nas decisões relativas aos direitos individuaes. 
O processo formativo da nacionalidade, como bem o ensina Schäffle, na Estructura e vida do corpo social, cnāo se prende sómente á raça ou á communidade da derivação; o centro de gravidade da nacionalidade não é mais a unidade pura de derivação, porque hoje nenhuma nação tem um sangue puro de todo o elemento heterogenen ; o centro de gravidade é a intima fusão espiritual, nascida não só da communidade da lingua nacional, como de outras forças que constituem o cimento social, das quaes a mais decisiva é a unidade na applicação das leis e regras que resolvem as relaçōes juridicas dos individuos».

A fixação dos ultimos Tribunaes no Rio de Janeiro teve logica consequencia, como declaração de um real estado de cousas, no acto de 16 de Dezembro de 1815, pelo qual o mesmo D. João VI elevou o Estado do Brasil á cathegoria politica de Reino Unido. Quando as Cortes Portuguezas, depois da volta de D. João VI, quizeram reagir contra as tendencias do Brasil para a separação, comprehenderam que, no Brasil, estava já formada uma nacionalidade; e, entāo, a primeira cousa que fizeram foi a Lei de 13 de Janeiro de 1822 extinguindo os Triburaes creados no Rio de Janeiro, reduzindo a Casa de Supplicação a uma Relação Provincial. O Principe Regente, depois D. Pedro I, que já estava no plano da Independencia do Brazil, comprehendeu o alcance dessa extincção dos Tribunaes; e, então, declarando que as leis e decretos das Cortes Geraes e Constituintes da Nação Portugueza, estavam sujeitas ao - cCumpra-se do Principe Regente, - recusou em virtude dos Avisos de 21 de Janeiro e 4 de Maio de 1822, cumprir a lei de 13 de Janeiro e manteve a Casa de Supplicação do Rio de Janeiro, tal como ficou instituida pelo Alvará de 10 de Maio de 1808. No Manifesto de 6 de Agosto de 1822, o Principe dizia que sextinctos os Tribunaes e obrigado o Brazil a buscar em Portugal a justiça, só restaria ao Brasil ser riscado do numero das Nações e Povos livres, ficando outra vez reduzido ao estado colonials. Para manter o Brazil como nação, foi preciso, pois, ligar ao Brazil, pela manutenção dos Tribunaes superiores, a solução das relações de direito entre os individuos que compunham o corpo social. Si o Principe Regente não tivesse negado o ‘cumpra-se» á Lei Portugueza de 13 de Janeiro de 1822, seria bem difficil que a independencia nacional tivesse sido proclamada em 7 de Setembro de 1822 ; o resultado seria ou a volta ao estado colonial, ou a revolução separatista, que, longe de manter a unidade do Brasil, produziria uma multiplicidade de nações.

O simperio» do Brasil, isto é, a unidade formal da Nação Brasileira, assim evolutivamente nascida da nossa historia, em 1808, mantido pela Constituição da Monarchia Constitucional, em 1824, foi sindissoluvelmente perpetuados pela Constituição da Republica Federativa, em 1890.

$$
\text { JoĀo MENDES JUNIOR }
$$

